\begin{tabular}{|c|c|c|}
\hline $\begin{array}{l}\text { EXCELLENT } \\
\text { PUBLISHERS } \\
\end{array}$ & $\begin{array}{l}\text { International Journal of Current Research } \\
\text { and Academic Review } \\
\text { ISSN: 2347-3215 (Online) } \\
\text { Journal homepage: http://www.ijcrar.com }\end{array}$ & 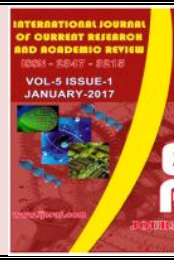 \\
\hline
\end{tabular}

doi: http://dx.doi.org/10.20546/ijcrar.2017.501.012

\title{
Prognosis of Stroke Patients who need Mechanical Ventilator
}

\author{
Aqeel K. Hatem* \\ Consultant Neurologist /Baghdad teaching hospital/Medical city complex, Iraq \\ *Corresponding author
}

\begin{abstract}
Stroke is ranked as the second leading cause of death worldwide with an annual mortality rate of 5.5 million. The burden of stroke does not only lie in the high mortality but the high morbidity also results in up to $50 \%$ of survivors being chronically disabled. Prospective cross-sectional study with 52 stroke patients. The mean age of patients was $(67.3 \pm 5$.3years old) and the male more than female. A significant association was found between the sex and death. (80.7\%) of the patients with Ischemic type of stroke. Bad prognosis of stroke patients who need mechanical ventilator was found in this study.
\end{abstract}

\section{Article Info}

Accepted: 10 January 2017

Available Online: 20 January 2017

Keywords

Stroke, Mechanical ventilation.

\section{Introduction}

According to the definition proposed by the World Health Organization in 1970, "stroke is rapidly developing clinical signs of focal (or global) disturbance of cerebral function, with symptoms lasting $24 \mathrm{~h}$ or longer, or leading to death, with no apparent cause other than of vascular origin" (Warlow, 1998). Recently, a new definition of stroke has been proposed by the American Stroke Association which is tissue-based and states that "stroke is an episode of acute neurological dysfunction presumed to be caused by ischemia or hemorrhage, persisting $\geq 24$ hours or until death" (Sacco et al., 2013). The clinical manifestations of stroke include a wide range of signs and symptoms such as paralysis, weakness, numbness, severe headache, slurred speech, mental status change, vision problems, falling and dizziness. A stroke may be described as a silent stroke if it occurs without clinical features. In a silent stroke either a silent area of the brain is involved or symptoms are not noticed (Sampane-Donkor, 2014).
Types of Stroke: Stroke is divided into thrombotic and embolic

\section{Ischemic stroke}

Ischemic stroke, that includes TIA, is the most common type of stroke is a blockage that cuts off blood supply to affected parts of the brain. Ischemic strokes are often referred to as cerebrovascular accidents (CVA) and could be a thrombotic or embolic event. The effects of the blockage are related to the location of the blockage in the brain rather than the source; however the source becomes vitally important in identifying the cause for individual management and secondary stroke prevention (Kwiatkowski, 2013).

A thrombotic ischemic stroke occurs when a diseased or damaged artery supplying blood to the brain forms a clot and pieces of that clot can break away and block a large or small vessel within the brain. An embolic stroke is 
caused by a blood clot that has formed elsewhere in the body (emboli) becomes dislodged and travels to a cerebral artery (MFMER, 2013). When an embolic stroke occurs, there are almost immediate neurological and physical deficits. Emboli may be bacterial in nature, form as a result of cardiac arrhythmias (atrial fibrillation), vascular repair process, or are dislodged vascular plaques. A transient ischemic attack (TIA) produces stroke symptoms that resolve when the arterial blockage is dislodged or dissolved spontaneously without medical intervention. Considers TIA's to be high risk since $9.5 \%$ of those with a TIA will subsequently have a more severe ischemic stroke within 90 days. The opportunity for secondary prevention makes a TIA an extremely important medical event.

\section{Hemorrhagic stroke}

Intracerebral hemorrhagic stroke differs from an ischemic stroke in that it is caused by a ruptured blood vessel as opposed to a blood clot. The ruptured vessel interrupts blood flow and delivery of essential nutrients and oxygen to the affected area of the brain. A ruptured blood vessel may release blood very rapidly which may lead to a sudden build up in cerebral pressure resulting inunconsciousness or death. Approximately $10-15 \%$ of all strokes are hemorrhagic and have an estimated $40 \%$ 50\% mortality rate (Woo et al., 2004). Goldstein et al. (2001) determined that "hypertension is a major risk factor for both cerebral infarction and intracerebral hemorrhage.

Other causes of intracerebral hemorrhages include infections, trauma, abnormalities in the blood vessels and blood clotting deficiencies Intracerebral hemorrhages are less common than ischemic strokes and only account for approximately $12 \%$ of stroke events. Another kind of hemorrhagic stroke is subarachnoid hemorrhage. This is similar to intracerebral hemorrhages in that such strokes are caused from a ruptured blood vessel; however these occur outside of the brain tissue itself and result in the subarachnoid space surrounding the brain to fill up with blood causing rapid loss of consciousness and a poor prognosis for full recovery. The most common cause is the rupture of a cerebral aneurysm.

Aneurysms may develop from birth or early childhood and grow very slowly over the years as a result of thinning and progressive damage of the artery walls. In summary ischemic strokes are the most common type of stroke in both men and women and has been linked to many underlying influences known as risk factors.
Mortality appears higher with those who develop hemorrhagic strokes.

\section{Epidemiology}

Stroke was the second most frequent cause of death worldwide in 2012, accounting for 6.7 million deaths. Approximately 17 million people had a stroke in 2010 and 33 million people have previously had a stroke and were still alive making total population of 50 million with stroke in the world. Stroke is the number one preventable cause of permanent disability. Projections show that by 2030 , stroke prevalence will increase by more than 20\% over 2012 (Javed, 2015). Between 1990 and 2010 the number of strokes decrease by approximately $10 \%$ in the developed world and increased by $10 \%$ in the developing world. Overall, two thirds of strokes occurred in those over 65 years old (Feigin et al., 2010) South Asians are at particularly high risk for stroke, accounting for $40 \%$ of global stroke deaths (Indian Heart Association Why South Asians Facts Web, 2015).

It is ranked after heart disease and before cancer. In the United States stroke is a leading cause of disability, and recently declined from the third leading to the fourth leading cause of death (Towfighi et al., 2011) Geographic disparities in stroke incidence have been observed, including the existence of a "stroke belt" in the southeastern United States, but causes of these disparities have not been explained. The incidence of stroke increases exponentially from 30 years of age, and etiology varies by age (Ellekjær et al., 1997). Advanced age is one of the most significant stroke risk factors. 95\% of strokes occur in people age 45 and older, and two-thirds of strokes occur in those over the age of 65. A person's risk of dying if he or she does have a stroke also increases with age. However, stroke can occur at any age, including in childhood. Family members may have a genetic tendency for stroke or share a lifestyle that contributes to stroke. Higher levels of Von Willebrand factor are more common amongst people who have had ischemic stroke for the first time (Bongers et al., 2006). The results of this study found that the only significant genetic factor was the person's blood type. Having had a stroke in the past greatly increases one's risk of future strokes.

\section{Mechanical ventilation}

Mechanical ventilation is a life-saving technological intervention for patients whose respiratory function is 
compromised due to an acute or chronic disease. Tracheal intubation and mechanical ventilation are indicated in patients with a large hemispheric stroke when progressive drowsiness reduces the ability to protect the airway. In other patients, ineffective ventilation from brainstem compression, aspiration, or any other type of lung injury may necessitate ventilator support. Previous studies revealed that patients with stroke who are comatose on admission and those requiring mechanical ventilation have a poor prognosis despite intensive care treatment (Qutub, 2001).

\section{Patients and Methods}

Study design and setting: A prospective cross-sectional study carried out for 2 years duration in the neurosciences hospital from the period of the first of October 2012 to the end of Sep. 2014.

Sample size: 52 stroke patients who admitted to the ICU requiring mechanical ventilation and within the age $\geq 55$ years old were included in this study. Data was collected by using a specially designed questionnaire and all patients assessed for GCS and MRI was done to detect the type of stroke.

Statistical analysis: All patients' data entered using computerized statistical software; Statistical Package for Social Sciences (SPSS) version 21 was used. Descriptive statistics presented as (mean \pm standard deviation) and frequencies as percentages. Kolmogorov Smirnov analysis verified the normality of the data set. Multiple contingency tables conducted and appropriate statistical tests performed, level of significance ( $p$ value) set at $\leq$ 0.05 .

\section{Results and Discussion}

The patients group consist of 41 men $(78.8 \%)$ and women $11(21.2 \%)$, and the mean age was $(67.3 \pm 5.3)$ years and the mean GCS score on admission was 10.2 for ischemic and 9.8 for hemorrhagic stroke patients, 43 patients (more than 82\%) were died, 46 (88.4) were admitted to the NICU within 24 hours after the onset of the symptoms. $42(80.7 \%)$ of the patients presented with ischemic stroke and the rest with spontaneous hemorrhage.

Table 2 show that $90.2 \%$ of the male was died and only $9.8 \%$ become well, while in female $54.5 \%$ of them was died and the rest become well. 26 patients was in age group (60-69) was died.

It has been found that there is a significant association between the gender difference and the survival outcome in which male had poor prognosis than that of female. While no significant differences was found regarding to the age, type of stroke and the survival outcome (table 2).

In the current study $(67.3 \pm 5.3)$ years was the mean age of stroke patients which is concordant with many studies done in developing countries (El Sayed et al., 1999; Cheung et al., 2007; Dalal et al., 2005) also with AlAsadi et al., studies which is done in Basrah in Iraq in 2014 (2014).More than half of the patients was within the age group 60-69 and the male was more predominant than female which is similar to that found by a previous study done in Iraq by Sulaiman, in 2002 (2002), Moreover it is similar to the Minelli study in Brazil in 2007 (2007) and with Mihalka in 2001 in West Ukrain (2001).

Table 1. Demographic characteristics of the patients

\begin{tabular}{|c|c|c|}
\hline & No. & $\%$ \\
\hline \multicolumn{3}{|l|}{ Age (years) } \\
\hline $50-59$ & 13 & 25 \\
\hline $60-69$ & 29 & 55.8 \\
\hline$\geq 70$ & 10 & 19.2 \\
\hline Total & 52 & 100.0 \\
\hline \multicolumn{3}{|l|}{ Type of stroke } \\
\hline Ischemic & 42 & 80.7 \\
\hline Hemorrhagic & 10 & 19.3 \\
\hline \multicolumn{3}{|c|}{ Time of admission to the NICU } \\
\hline$\leq 24 \mathrm{hrs}$ & 46 & 88.4 \\
\hline$\geq 24 \mathrm{hrs}$ & 6 & 11.6 \\
\hline
\end{tabular}


Table 2. Survival outcome of patients

\begin{tabular}{|c|c|c|c|c|c|c|c|c|}
\hline \multirow[t]{2}{*}{ variable } & \multicolumn{2}{|c|}{ Died } & \multicolumn{2}{|c|}{ Well } & \multicolumn{2}{|l|}{ Total } & \multirow[t]{2}{*}{$\chi^{2}$} & \multirow{2}{*}{$\begin{array}{l}\mathrm{P}- \\
\text { value }\end{array}$} \\
\hline & No. & $\%$ & No. & $\%$ & No. & $\%$ & & \\
\hline \multicolumn{9}{|l|}{ Gender } \\
\hline Male & 37 & 90.2 & 4 & 9.8 & 41 & 100.0 & \multirow[t]{2}{*}{5.43} & \multirow[t]{2}{*}{0.01} \\
\hline Female & 6 & 54.5 & 5 & 45.5 & 11 & 100.0 & & \\
\hline \multicolumn{9}{|l|}{ Age } \\
\hline $50-59$ & 9 & 69.2 & 4 & 30.8 & 13 & 100.0 & \multirow[t]{3}{*}{2.68} & \multirow[t]{3}{*}{0.2} \\
\hline $60-69$ & 26 & 90.0 & 3 & 10.0 & 29 & 100.0 & & \\
\hline$\geq 70$ & 8 & 80.0 & 2 & 20.0 & 10 & 100.0 & & \\
\hline \multicolumn{9}{|l|}{ Type of stroke } \\
\hline Ischemic & 34 & 81.0 & 8 & 19.0 & 42 & 100.0 & \multirow[t]{2}{*}{0.04} & \multirow[t]{2}{*}{0.8} \\
\hline Hemorrhagic & 9 & 90.0 & 1 & 10.0 & 10 & 100.0 & & \\
\hline
\end{tabular}

Fig 1. Gender distribution of cases

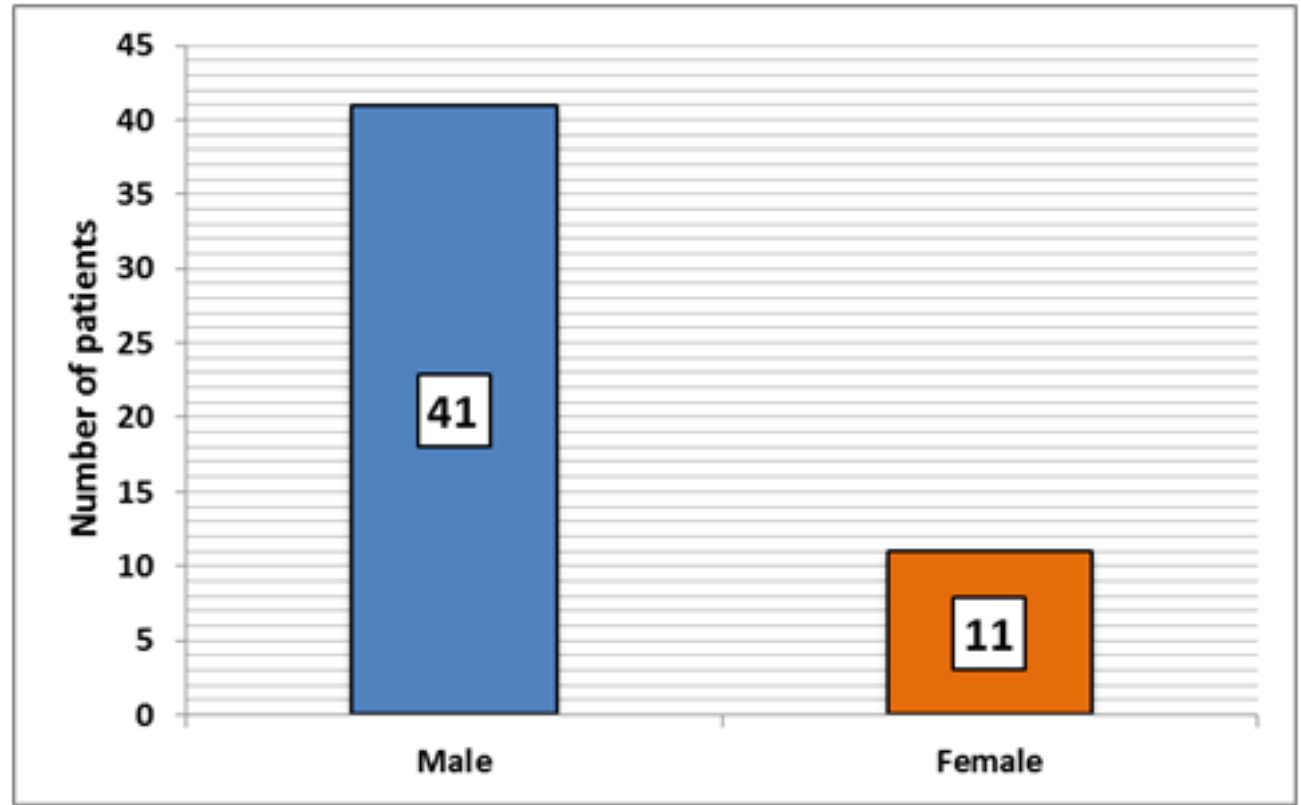

More than $4 / 5^{\text {th }}(80.7 \%)$ of the stroke patients in the present study were ischemic type and the rest was hemorrhagic consistent with that registered by Hamad et al., in Qatar in 2001 (2001) were 80\% of the stroke patients was ischemic type. Also it is similar to that registered in a study done in Saudia Arabia by El-Sayed (El Sayed et al., 1999) in 1999. This may be explained by that most Arabic Gulf people are adopting Western lifestyle and dietary habits, including increased fat intake, cigarette smoking and decreased physical activity.

Regarding to the time of admission to the NICU in the current study it was registered that $88.4 \%$ of the stroke patients admitted to these unit within 24 hours. This is concordant with Steiner, Thorsten, et al. (1997) in which he mentioned that most of the patients were admitted to the NICU within 24 hours after onset of symptoms.

Limitation of the study: this study was a single center study with small sample size so we can't generalize the result.

\section{Conclusion}

The present study show that the stroke was more common in male than female, also it is increase with age (60 years and more) and the Ischemic stroke is most 
common type than hemorrhagic. Bad prognosis was registered with the stroke patients who need mechanical ventilation.

\section{References}

Al-Asadi, J.N., Habib, H.A. 2014. Risk factors and 30day case fatality of first-ever stroke in Basrah, Iraq. Nigerian medical journal: J. Nigeria Med. Assoc., 55(3):209.

Al-Rajeh, S., Awada, A., Niazi, G., Larbi, E. 1993. Stroke in a Saudi Arabian National Guard Community. Analysis of 500 consecutive cases from a population-based hospital. Stroke, 24:1635.

Bongers, T.N., de Maat, M.P., van Goor, M.L., Bhagwanbali, V., van Vliet, H.H., Gómez García, E.B., Dippel, D.W., Leebeek, F.W. 2006. "High von Willebrand factor levels increase the risk of first ischemic stroke: influence of ADAMTS13, inflammation, and genetic variability". Stroke, 37(11): 2672-7.

Cheung, C.M., Tsoi, T.H., Hon, S.F., Au-Yeung, M., Shiu, K.L., Lee, C.N., et al. 2007. Outcomes after first-ever stroke. Honk Kong Med. J., 13: 95-9.

Dalal, P.M., Bhattacharjee, M., Vairale, J., Bhat, P. 2008. Mumbai Stroke Registry (2005-2006) Surveillance using WHO Steps Stroke Instrument--Challenges and Opportunities. J. Assoc. Physicians India, 56: 675-80.

Donnan, G.A., Fisher, M., Macleod, M., Davis, S.M. 2008. "Stroke". Lancet, 371(9624): 1612-23.

El Sayed, M.M., Adeuja, A.O., El-Nahrawy, E., Olaish, M.A. 1999. Characteristics of stroke in Hofuf, Saudi Arabia. Annals of Saudi med., 19: 27-31.

Ellekjær, H., Holmen, J., Indredavik, B., Terent, A. 1997. Epidemiology of stroke in Innherred, Norway, 1994 to 1996 Incidence and 30-day case-fatality rate. Stroke, 28(11): 2180-4. Retrieved 2008-01-22.

Feigin, V.L., Forouzanfar, M.H., Krishnamurthi, R., Mensah, G.A., Connor, M., Bennett, D.A., et al. 2010. Global and regional burden of stroke during 1990-2010: findings from the Global Burden of Disease Study 2010. The Lancet, 383(9913): 24555.

Goldstein, L.B., Adams, R., Becker, K., Furberg, C.D., Gorelick, P.B., Hademenos, G., Hill, M., Howard, G., Howard, V.J., Jacobs, B., Levine, S.R. 2001. Primary prevention of ischemic stroke A statement for healthcare professionals from the stroke council of the American heart association. Circulation, 103(1):163-82.
Hamad, A., Hamad, A., Sokrab, T.E., Momeni, S., Mesraoua, B., Lingren, A. 2001. Stroke in Qatar: A one-year, hospital-based study. J. Stroke Cerebrovasc. Dis., 10: 236-41.

Indian Heart Association Why South Asians Facts Web. 2015. Available at: http://indianheartassociation.org/why-indians-whysouth-asians/overview/accessed on 10/12/2015

Javed, M.A. 2015. Journey over four decades to discover new definitions of stroke and TIA for 21st century: are we ready for the change?. Pakistan J. Neurol. Sci. (PJNS), 10(1): v-ii.

Khan, S.N., Vohra, E.A. 2007. Risk factors for stroke: A hospital based study. Pak. J. Med. Sci., 23: 17-22.

Kwiatkowski, B. 2013. Stroke in Saskatchewan: a regional sample.A Thesis Submitted to the College of Graduate Studies and Research in Partial Fulfillment of the Requirements for the Degree of Master of Nursing in the College of Nursing University of Saskatchewan Saskatoon.

Lloyd-Jones, D., Adams, R.J., Brown, T.M., Carnethon, M., Dai, S., De Simone, G., Ferguson, T.B., Ford, E., Furie, K., Gillespie, C., Go, A. 2010. Heart disease and stroke statistics-2010 update A report from the American Heart Association. Circulation, 121(7):e46-215.

Mihalka, L., Smolanka, V., Bulecza, B., Mulesa, S., Bereczki, D. 2001. A population study of stroke in West Ukraine: Incidence, stroke services, and 30day case fatality. Stroke, 32: 2227-31.

Minelli, C., Fen, L.F., Minelli, D.P. 2007. Stroke incidence, prognosis, 30-day, and 1-year fatality rates in Matao, Brazil: A population-based prospective study. Stroke, 38: 2906-11.

Qutub, H.O. 2001. Ischemic strokes requiring mechanical ventilation in the Intensive Care Unit. Neurosciences (Riyadh, Saudi Arabia), 6(2): 103-5.

Sacco, R.L., Kasner, S.E., Broderick, J.P., Caplan, L.R., Culebras, A., Elkind, M.S., George, M.G., Hamdan, A.D., Higashida, R.T., Hoh, B.L., Janis, L.S. 2013. An updated definition of stroke for the 21st century a statement for healthcare professionals from the American Heart Association/American Stroke Association. Stroke, 44(7): 2064-89.

Sampane-Donkor, E. 2014. A Study of Stroke in Southern Ghana: Epidemiology, Quality of Life and Community Perceptions (Doctoral dissertation, University of Iceland).

Senelick, R.C., Dougherty, K. 2001. Living with stroke: A guide for families. Delmar Pub.

Steiner, T., Mendoza, G., De Georgia, M., Schellinger, P., Holle, R., Hacke, W. 1997. Prognosis of stroke 
patients requiring mechanical ventilation in a neurological critical care unit. Stroke, 28(4): 711-5.

Sulaiman, N.F., Khalil, A.I., Al-Mahdawi, A. 2002. Evaluation of stroke patients. Iraq J. Comm. Med., 15: 64-8.

Towfighi, A., Saver, J.L. 2011. Stroke declines from third to fourth leading cause of death in the United States historical perspective and challenges ahead. Stroke, 42(8): 2351-5.
Warlow, C.P. 1998. Epidemiology of stroke. Lancet, 352: 1-4.

Woo, D., Haverbusch, M., Sekar, P., Kissela, B., Khoury, J., Schneider, A., Kleindorfer, D., Szaflarski, J., Pancioli, A., Jauch, E., Moomaw, C. 2004. Effect of untreated hypertension on hemorrhagic stroke. Stroke, 35(7): 1703-8.

\section{How to cite this article:}

Aqeel K. Hatem. 2017. Prognosis of Stroke Patients who Need Mechanical Ventilator. Int.J.Curr.Res.Aca.Rev. 5(1), 98-103. doi: http://dx.doi.org/10.20546/ijcrar.2017.501.012 